\title{
34th International mammalian genome conference: meeting overview
}

\author{
Darla R. Miller ${ }^{1} \cdot$ Linda D. Siracusa ${ }^{2}$ (1) \\ Received: 29 April 2021 / Accepted: 21 May 2021 / Published online: 5 June 2021 \\ (c) The Author(s), under exclusive licence to Springer Science+Business Media, LLC, part of Springer Nature 2021
}

\begin{abstract}
The 34th International Mammalian Genome Conference (IMGC) was held in conjunction with The Allied Genetics Conference (TAGC2020). Scientists from more than 30 countries participated in TAGC2020 to share advances in genetics and genomics research across species. The mammalian section, represented mostly by International Mammalian Genome Society (IMGS) members, had 239 in-person registrants and the number of registrants grew to 3520 virtual attendees when the meeting was converted from an in-person format to a virtual format. A diverse attendance of pre-doctoral and post-doctoral trainees, young investigators, established researchers, clinicians, bioinformaticians, and computational biologists enjoyed a rich scientific program selected from 184 submitted (Mammalian) abstracts in the fields of epigenetics, system genetics, developmental biology, cancer, human disease modeling, technical advances, and bioinformatics.
\end{abstract}

\section{Introduction}

The Allied Genetics Conference (TAGC2020) was hosted by the Genetics Society of America (GSA). It was originally scheduled to be held at the Gaylord National Resort \& Convention Center in National Harbor, Maryland on April 22-25, 2020. Due to the global spread of COVID-19, the GSA worked quickly and diligently to successfully convert the meeting to a virtual format. While this format was new, the meeting provided the ability to have oral and poster presentations as well as workshops on-line.

The GSA has pioneered this conference which focused on the genetics of model organisms into one meeting every 4-5 years since 2011. TAGC2020 included participants from across the $C$. elegans, Drosophila, population, evolutionary, and quantitative genetics (PEQG), Xenopus, yeast, zebrafish, and mammalian communities. The schedule was divided between concurrent community sessions and larger thematic plenary sessions. Talks for the thematic sessions were chosen from invited speakers and submitted abstracts

Linda D. Siracusa

Linda.Siracusa@hmhn.org

Darla R. Miller

millerdr@med.unc.edu

1 Department of Genetics, The University of North Carolina at Chapel Hill, Chapel Hill, NC, USA

2 Department of Medical Sciences, Hackensack Meridian School of Medicine, Nutley, NJ, USA from all communities. Attendees were allowed to participate free of charge, with the only requirement being preregistration. Overall, the virtual TAGC2020 had more than 18,000 participants!

The transformation of such a large meeting from in-person to on-line in less than two months required the hard work of a dedicated team of leaders from across the communities as well as a core of organizers from within the GSA. The IMGS had previously worked with the GSA on prior TAGC meetings in 2011 and 2016, and continued its role of organizing the mammalian portion of the meeting for TAGC2020. The IMGS acknowledges the exceptional contributions of the entire GSA leadership team for their dedication to moving the science forward and making TAGC2020 a success.

\section{The IMGS Trainee Symposium}

The IMGS Trainee Symposium was held on April 16, 2020, a few days before the start of the main meeting. The Trainee Symposium served to familiarize organizers, trainees, and participants from the mammalian community with the online format as well as to continue the training tradition which is central to the mission of the IMGS.

A total of 14 excellent talks were delivered by IMGS trainees, of which 3 received The Lorraine Flaherty Award (cash prizes were awarded this year in lieu of a formal presentation in the main meeting). Kristen Barratt, Ph.D. was presented with the Verne Chapman Young Scientist Award 
for her platform presentation. IMGS Secretariat members served as judges throughout the Trainee Symposium as well as evaluated more than 50 trainee posters. All trainee award winners (oral talks and posters) along with the titles of their presentations are shown in Table 1.

\section{Selected Highlights of TAGC2020}

TAGC2020 officially opened on-line on April 22, 2020 with keynote speakers from across the communities and annual award presentations by the GSA. The next sets of sessions were specifically focused on model organisms and ran simultaneously.

For the mammalian portions, session themes for oral presentations focused on Disease Models and Aging, Gene Regulation, Genomics and Systems Biology, and New Technology and Resources. The Scientific Organizers of the mammalian section of TAGC2020 were Steven Munger (Chair, The Jackson Laboratory), Martin Hrabĕ de Angelis (Helmholtz Zentrum München), Darla Miller (UNC Chapel Hill), Fernando Pardo-Manuel de Villena (UNC Chapel Hill), and Linda Siracusa (Hackensack Meridian School of Medicine). Three special features of the TAGC2020 are highlighted below.

\section{Genomics of SARS-CoV-2}

Two keynote talks were given by Richard Neher (University of Basel) and Lea Starita (University of Washington) who work on the sequencing/genetic analyses of SARS-CoV-2 isolates and the development of novel methods for testing for SARS-CoV-2, respectively. Their talks described outstanding research coupled with collaborative efforts on a scale that is changing how we perform science across the world. Both speakers shared insights into the evolution of the pandemic, the spread of variants, the varied approaches to testing, as well as placed the meeting into the context of a global pandemic.

\section{Diversity, Equity, and Inclusion}

The session on diversity, equity, and inclusion ranged from approaches to expand inclusion of underrepresented groups in higher education to research leading to genomic analyses of indigenous populations. Presentations focused on (1) factors to improve the graduate admissions process (Scott Barolo, University of Michigan Medical School), (2) development and execution of a graduate-student led Diversity Preview Weekend to familiarize students

Table 1 International Mammalian Genome Society award winners for 2020

\begin{tabular}{|c|c|c|c|}
\hline Awardee & Institute & Title & Award \\
\hline Kristen Barratt & Australian National University & $\begin{array}{l}\text { Elevated canonical WNT signaling disrupts } \\
\text { heart development and may underlie cases } \\
\text { of human heterotaxy }\end{array}$ & $\begin{array}{l}\text { Verne Chapman Young Scien- } \\
\text { tist Award-OOP }\end{array}$ \\
\hline Uma Arora & The Jackson Laboratory & $\begin{array}{l}\text { Evolutionary genomics of centromeric } \\
\text { satellites in house mice }(M u s)\end{array}$ & Lorraine Flaherty Award-OOP \\
\hline Candice Byers & The Jackson Laboratory & $\begin{array}{l}\text { Divergence in KRAB zinc finger proteins is } \\
\text { associated with pluripotency spectrum in } \\
\text { mouse embryonic stem cells }\end{array}$ & Lorraine Flaherty Award-OOP \\
\hline Danfeng Cai & $\begin{array}{l}\text { Howard Hughes Medical Institute, Ashburn, } \\
\text { VA }\end{array}$ & $\begin{array}{l}\text { Phase separation of YAP reorganizes } \\
\text { genome topology for long-term YAP } \\
\text { target gene expression }\end{array}$ & Lorraine Flaherty Award-OOP \\
\hline Kari Chesney & University of Missouri & $\begin{array}{l}\text { Exposure to environmental triggers results } \\
\text { in disease signs in rats carrying a human } \\
\text { ATG16L1 Crohn's disease susceptibility } \\
\text { variant }\end{array}$ & Poster Award \\
\hline Elena Mogilyansky & Hackensack Meridian School of Medicine & $\begin{array}{l}\text { Gastrointestinal tumor phenotypes in } \\
\text { offspring of collaborative cross mice and a } \\
\text { sensitized line }\end{array}$ & Poster Award \\
\hline Adelaide Tovar & University of North Carolina-Chapel Hill & $\begin{array}{l}\text { A GxE QTL on chromosome } 15 \text { underlies } \\
\text { susceptibility to air pollution-induced lung } \\
\text { injury in mice }\end{array}$ & Poster Award \\
\hline Montana Lara & University of Vermont & $\begin{array}{l}\text { Network-based functional prediction } \\
\text { augments genetic association to predict } \\
\text { candidate genes for inflammatory bowel } \\
\text { disorder in mice }\end{array}$ & $\begin{array}{l}\text { Outstanding nomenclature on } \\
\text { a research poster-ICSGNM }\end{array}$ \\
\hline
\end{tabular}

$O O P$ outstanding oral presentation, ICSGNM international committee on standardized genetic nomenclature for mice 
of diverse backgrounds with graduate school (Andrea Darby, Cornell University), (3) describing the work of the inclusive environments and metrics in biology education and research (iEMBER) Network to address diversity, equity and inclusion in STEM fields (Gary McDowell, Lightoller LLC), (4) research on cultural dietary practices and signaling pathways led by high school students from diverse backgrounds (Jennifer Alexander, Fox Chase Cancer Center), and (5) establishment of the first tribal-led biobank in the United States, the native biodata consortium (NBC), whose goal is to facilitate genomic analyses of indigenous people, so tribal nations can have the knowledge over genomic and data sovereignty (Krystal Tsosie, Vanderbilt University).

\section{Workshops}

A diversity of workshops were open to all meeting participants. A benefit of the virtual format was that workshop times were not restricted to the duration of the meeting. In fact, workshop dates ranged from May 7, 2020 to July 13, 2020 and enabled participants to attend one, some, or all of the offerings. Workshop leaders and topic titles are detailed in Table 2.

\section{TAGC2020 Materials are Available On-Line}

Overall, TAGC2020 emphasized how the C. elegans, Drosophila, PEQG, Xenopus, yeast, and zebrafish, and mammalian communities are moving forward with new discoveries that deepen our understanding of genetic mechanisms and their relationship to development and disease across species. TAGC2020 emphasized the critical role of model organisms in advancing research in genetics and genomics.

Similar to previous meetings (Moskowitz et al. 2019, Sanchez-Andrade et al. 2018; Tracey et al. 2020), the 34th IMGC brought researchers together (albeit for the first time in a virtual format) to share their latest results. The development of cutting-edge technologies for genetic manipulation, single cell and global genomic/transcriptomic/proteomic profiling, along with digital in situ visualization of cellular pathways within tissues enabled researchers to delve more deeply into the complexity of disease phenotypes, developmental processes, and biomedical applications. Special presentations on public database resources included talks about the Rat Genome Database (RGD) providing access to consolidated disease-related information across species (Jennifer R. Smith, Medical College of Wisconsin), the mouse Gene Expression Database (GXD) providing an integrated tool to search for disease-related expression in tissues using standardized annotations (Constance Smith, The Jackson Laboratory), and the integration of expression data by

Table 2 TAGC2020 workshops

\begin{tabular}{|c|c|c|}
\hline Title & Date & Leaders \\
\hline Science communication: challenges and impact & $5-7-20$ & $\begin{array}{l}\text { Thomas Merritt, Adelita D. Mendoza, Angel Cisneros, Haifa } \\
\text { Alhadyian, Jessica Velez, Vandana Raghavan, Carla Bautista } \\
\text { Rodriguez }\end{array}$ \\
\hline Publishing Q\&A & $5-19-20$ & GSA Journals \\
\hline Career development workshop & $5-19-20$ & $\begin{array}{l}\text { GSA's Early Career Leadership Career Development Subcom- } \\
\text { mittee }\end{array}$ \\
\hline $\begin{array}{l}\text { Chemoreception, physiology, and social behavior: a genetic per- } \\
\text { spective }\end{array}$ & $5-21-20$ & Yali Zhang \\
\hline $\begin{array}{l}\text { Raising a woke generation of geneticists: how and why to include } \\
\text { eugenics history in genetics classes }\end{array}$ & $5-26-20$ & Michele Markstein, Gregory Davis \\
\hline $\begin{array}{l}\text { Reproducibility for everyone: strategies to maximize your work's } \\
\text { impact }\end{array}$ & $5-28-20$ & $\begin{array}{l}\text { Nele Haelterman, Lenny Teytelman, Angela Abitua, April } \\
\text { Clyburne }\end{array}$ \\
\hline Grants \& funding & $6-2-20$ & GSA \\
\hline $\begin{array}{l}\text { Metabolic plasticity: exploring the flexibility of metabolic net- } \\
\text { works in the context of development, evolution, environmental } \\
\text { stress, and disease }\end{array}$ & $6-2-20$ & Jason Tennessen, Kristi Montooth, Marion Walhout \\
\hline Genetic puzzles & $6-4-20$ & Didier Stainier, Coleen Murphy \\
\hline Single cell approaches in animal development & $6-16-20$ & James Gagnon, John Murray \\
\hline Scientific writing workshop & $6-16-20$ & BioKansas \\
\hline $\begin{array}{l}\text { Cultivating communities: making sense of host-microbiome inter- } \\
\text { actions through the lens of genetics }\end{array}$ & $6-18-20$ & Buck Samuel, Nichole Broderick, Cara Haney \\
\hline BREW: bridging research and education workshop & $7-13-20$ & Mary Miller, Pamela Hanson, Jill Keeney \\
\hline
\end{tabular}


GENCODE as part of its efforts to fully annotate the mouse and human genomes (Jane Loveland, European Molecular Biology Institute).

Despite researchers having to adapt to a global pandemic, the incredible accomplishments of scientists, clinicians, and trainees this past year were evident from the diversity of biological systems described across sessions at the TAGC2020. We encourage you to search for details about TAGC2020 at https://genetics-gsa.org/tagc-2020/. Abstracts and the entire program for TAGC2020 are freely available on-line at https:/genetics-gsa.org/tagc-2020/wp-content/uploads/ sites/4/2020/04/200421-TAGC20-Abstract-Book-v1a.pdf

\section{The 35th International Mammalian Genome Society Meeting}

IMGS meeting participants elegantly highlighted and illustrated how recent advances in mammalian genetic and genomic approaches have improved our ability to decipher complex biological mechanisms and disease processes. The 35th IMGC is scheduled for February 27-March 3, 2022 in Vancouver, Canada. This meeting will be the first time the IMGS will host its annual meeting in Canada. However, the COVID-19 pandemic continues to be of concern and the IMGS Secretariat will review the situation at its next meeting. Alternate formats (hybrid or virtual) are being planned. Updates on the 35th IMGC can be found at www.imgs.org

Acknowledgements The 34th IMGC was jointly organized by the GSA and the IMGS. The IMGS sincerely thanks the organizers, namely Suzy Brown (GSA), Tracey Pellegrin-Connelly (GSA), and Steve Munger (GSA) along with Darla Miller (IMGS) who worked very hard and provided invaluable logistical support to make the on-line meeting a success. The IMGS extends its gratitude to Secretariat members, Linda Siracusa (President), Fernando Pardo-Manuel de Villena (Vice President), Martin Hrabê de Angelis (Past-President), Kuniye Abe, Ruth
Arkell, Elizabeth Bryda, Junyue Cao, Yichen Dai, Kent Hunter, Laura Reinholdt, and Michelle Southard-Smith for their assistance in planning the conference and their service to the Society. The IMGS extends its gratitude to the Nominations and Elections Committee, comprising Beth Dumont (Chair), Anne-Marie Mallon, Lauryl Nutter, and Atsushi Yoshiki for their service to the Society. The IMGS also extends special thanks to Monica McAndrews (The Jackson Laboratory) for reviewing and correcting nomenclature in meeting abstracts as well as selecting the ICSGNM nomenclature award winner (Table 1). The mammalian portion of the meeting was supported in part by generous financial contributions from GeneSeek (Neogen), The International Society for Transgenic Technologies (ISTT), and The International Mammalian Genome Society (IMGS). Funding for the trainee presentation awards came directly from the IMGS. Funding for student scholarships was made possible by NIH Grant 2R13HG002394 from NHGRI, NIEHS, and NICHD.

\section{Declarations}

Conflict of interest The authors declare that they have no conflict of interest and no competing interests.

\section{References}

Moskowitz J, Tracey LJ, Widmayer S, Dumont B (2019) Meeting report: 32nd International Mammalian Genome Conference. Mamm Genome 30(3-4):43-53. https://doi.org/10.1007/ s00335-019-09797-1

Sanchez-Andrade G, Moskowitz J, Howe S, Gunn TM (2018) Meeting report: 31st International Mammalian Genome Conference, mammalian genetics and genomics: from molecular mechanisms to translational applications. Mamm Genome 29(5-6):299-309. https://doi.org/10.1007/s00335-018-9747-6

Tracey LJ, Noll KE, Montagutelli X (2020) 33rd International Mammalian Genome Conference: meeting highlights. Mamm Genome 31(3-4):69-76. https://doi.org/10.1007/s00335-020-09830-8

Publisher's Note Springer Nature remains neutral with regard to jurisdictional claims in published maps and institutional affiliations. 